\title{
Chronic resveratrol reverses a mild angiotensin Il-induced pressor effect in a rat model
}

\author{
This article was published in the following Dove Press journal: \\ Integrated Blood Pressure Control \\ 28 January 2016 \\ Number of times this article has been viewed
}

\author{
Kevin L Gordish' \\ William H Beierwaltes ${ }^{1,2}$ \\ 'Department of Physiology, \\ Wayne State School of Medicine, \\ ${ }^{2}$ Department of Internal Medicine, \\ Hypertension and Vascular Research \\ Division, Henry Ford Hospital, \\ Detroit, MI, USA
}

\begin{abstract}
Resveratrol is reported to reduce blood pressure in animal models of hypertension, but the mechanisms are unknown. We have shown that resveratrol infusion increases sodium excretion. We hypothesized that chronic ingestion of resveratrol would reduce angiotensin II (Ang II)-induced increases in blood pressure by decreasing oxidative stress and by also decreasing sodium reabsorption through a nitric oxide-dependent mechanism. We infused rats with vehicle or $80 \mu \mathrm{g}$ Ang II/d over 4 weeks. Vehicle or Ang II-infused rats were individually housed, pair fed, and placed on a diet of normal chow or normal chow plus $146 \mathrm{mg}$ resveratrol/d. Groups included 1) control, 2) resveratrol-fed, 3) Ang II-treated, and 4) Ang II plus resveratrol. Systolic blood pressure was measured by tail cuff. During the 4th week, rats were placed in metabolic caging for urine collection. $\mathrm{NO}_{2} / \mathrm{NO}_{3}$ and 8-isoprostane excretion were measured. Ang II increased systolic blood pressure in the 1 st week by $+14 \pm 5 \mathrm{mmHg}(P<0.05)$ in Group 3 and $+10 \pm 3 \mathrm{mmHg}(P<0.05)$ in Group 4, respectively. Blood pressure was unchanged in Groups 1 and 2. After 4 weeks, blood pressure remained elevated in Group 3 rats with Ang II $(+9 \pm 3 \mathrm{mmHg}, P<0.05)$, but in Group 4, blood pressure was no longer elevated $(+2 \pm 2 \mathrm{mmHg})$. We found no significant differences between the groups in sodium excretion or cumulative sodium balance $(18.49 \pm 0.12,17.75 \pm 0.16,17.97 \pm 0.17,18.46 \pm 0.18 \mu \mathrm{Eq} \mathrm{Na}+/ 7 \mathrm{~d}$ in Groups $1-4$, respectively). Urinary excretion of $\mathrm{NO}_{2} / \mathrm{NO}_{3}$ in the four groups was 1) $1631 \pm 207 \mu \mathrm{mol} / 24 \mathrm{~h}, 2$ ) $1045 \pm 236 \mu \mathrm{mol} / 24 \mathrm{~h}, 3) 1490 \pm 161 \mu \mathrm{mol} / 24 \mathrm{~h}$, and 4) $609 \pm 17 \mu \mathrm{mol} / 24 \mathrm{~h}$. 8-Isoprostane excretion was 1) $63.85 \pm 19.39 \mathrm{nmol} / 24 \mathrm{~h}, 2$ ) $73.57 \pm 22.02 \mathrm{nmol} / 24 \mathrm{~h}, 3) 100.69 \pm 37.62 \mathrm{nmol} / 24 \mathrm{~h}$, and 4) $103.00 \pm 38.88 \mathrm{nmol} / 24 \mathrm{~h}$. We conclude that chronic resveratrol supplementation does not blunt Ang II-increased blood pressure, and while resveratrol has mild depressor effects, these do not seem to be due to natriuresis or enhanced renal nitric oxide synthesis.
\end{abstract}

Keywords: resveratrol, angiotensin, natriuresis, sodium balance, sodium excretion

\section{Introduction}

Resveratrol is a polyphenol found in some foods, including the skins of grapes, red wine, and peanuts. It is proposed to be responsible for the beneficial effects of red wine consumption contributing possibly to reductions in oxidative stress and blood pressure. ${ }^{1,2}$ We were interested in whether a possible renal mechanism may explain how resveratrol lowers blood pressure in a rat model. Dolinsky et $\mathrm{al}^{3}$ showed that resveratrol was able to reduce increases in systolic pressure in spontaneously hypertensive rats (SHR) and mice infused with angiotensin II (Ang II) via osmotic minipumps. When resveratrol was removed, blood pressure of SHR increased to the same level of that of control SHR.

Nitric oxide (NO) plays a critical role in the regulation of blood pressure along with salt and water transport along the nephron. ${ }^{4-6}$ Mattson et $\mathrm{al}^{7}$ demonstrated that
Correspondence:William H Beierwaltes Department of Internal Medicine, Hypertension and Vascular Research Division, 7088 E\&R Building, Henry Ford Hospital, 2799 West Grand Boulevard, Detroit, MI 48202, USA

$\mathrm{Tel}+\mathrm{I} 3139167494$

Fax + I 3139165284

Email wbeierwl@hfhs.org (c) (1) () 2016 Gordish and Beierwaltes. This work is published and licensed by Dove Medical Press Limited. The full terms of this license are available at https://www.dovepress. com/terms.php and incorporate the Creative Commons Attribution - Non Commercial (unported, v3.0) License (httr:///creativecommons.org/licenses/by-nc/3.0). By accessing Press Limited, provided the work is properly attributed. For permission for commercial use of this work, please see paragraphs 4.2 and 5 of our Terms (https://www.dovepress.com/terms.php). 
NO supports natriuresis, and inhibition of NO within the kidney with $N \omega$-nitro-L-arginine had the effect of decreasing sodium and water excretion due to an unspecified mechanism. We previously published that resveratrol infusion resulted in renal vasodilation and also increased sodium excretion. ${ }^{8}$ The existing literature supports an interactive involvement between resveratrol and NO. Resveratrol has been shown to increase NO synthesis in multiple tissues. ${ }^{9-11}$ Defects in NO production have been implicated in hypertension. ${ }^{7,12}$ Endothelial NO synthase generated NO inhibits sodium reabsorption in the thick ascending limb. ${ }^{13,14}$ Gonzalez-Vicente et $\mathrm{al}^{9}$ have shown that resveratrol increases NO production in thick ascending limbs via a $\mathrm{Ca}^{2+} /$ calmodulin-dependent mechanism. The recognizable limitation of our previous study was that resveratrol was being directly infused into the bloodstream. It is unknown if dietary resveratrol supplementation can increase sodium excretion.

Ang II has widely been recognized as a potent pressor, inducer of oxidative stress, and regulator of cardiovascular and renal function. ${ }^{15}$ In addition to increasing total peripheral resistance and blood pressure, ${ }^{4}$ Ang II directly stimulates sodium reabsorption within the kidney and indirectly via the actions of aldosterone. ${ }^{16}$ Increased sodium reabsorption is linked to salt-sensitive increases in blood pressure. Ang II is recognized to increase oxidative stress and production of reactive oxygen species. Low, subpressor dose of Ang II in normotensive pigs has been shown to increase the concentration of freely circulating 8-isoprostane levels within the plasma. ${ }^{17}$ Ortiz et $\mathrm{al}^{18}$ showed that the pressor doses of Ang II increased isoprostane levels in Sprague Dawley rats. Further, the development of hypertension and the increased isoprostane levels were blunted with the addition of Ang II type-I receptor antagonists. ${ }^{18}$ Resveratrol treatment has been shown to decrease isoprostane production within the aged rat brain and in heart in a model of diabetic cardiomyopathy. ${ }^{19,20}$ Further, resveratrol treatment has also been shown to decrease urinary excretion of isoprostane in a mouse model of diabetes. ${ }^{21}$

On the basis of these observations, we hypothesized that chronic ingestion of resveratrol would reduce Ang II-induced increases in blood pressure by decreasing oxidative stress and by decreasing sodium reabsorption through a NO-dependent mechanism.

\section{General methods}

Male Sprague Dawley rats weighing 200-225 g were housed in a standard caging. Rats were fed normal chow containing $0.4 \%$ sodium (Harlan Teklad, Madison, WI, USA) and allowed free access to distilled water. Prior to the beginning of the experiment, rats were pretrained on a noninvasive tail cuff plethysmography multichannel system (Kent Scientific, Torrington, CT, USA) three times a week for 2 weeks to measure systolic blood pressure. All procedures were approved by the Henry Ford Health System Institutional Animal Care and Use Committee and adhered to the guiding principles in the care and use of experimental animals in accordance with the National Institute of Health guidelines. Henry Ford Hospital operates an Association for Assessment and Accreditation of Laboratory Animal Care (AAALAC)-accredited animal care facility.

\section{Diet assignment}

After the training period, rats were moved to individually housed caging and assigned to one of four groups: 1) control, consuming normal rat chow diet supplemented with $3 \mathrm{~g} / \mathrm{d}$ of the dietary resveratrol vehicle dark chocolate frosting (Duncan Hines, Cherryhill, NJ, USA) $(n=7) ; 2)$ normal rat chow supplemented with $3 \mathrm{~g} / \mathrm{d}$ of frosting containing $146 \mathrm{mg}$ of resveratrol (Cayman Chemical, Ann Arbor, MI, USA) $(n=8) ; 3)$ normal rat chow with frosting vehicle and administered Ang II ( $80 \mu \mathrm{g} / \mathrm{d})$ (Sigma-Aldrich Co., St Louis, MO, USA) intraperitoneally via an Alzet (Durect Corp., Cupertino, CA, USA) osmotic minipumps (implantation methodology outlined later) (n=7), and 4) Ang II ( $80 \mu \mathrm{g} / \mathrm{d})$ intraperitoneally supplemented with $146 \mathrm{mg}$ resveratrol in $3 \mathrm{~g} / \mathrm{d}$ frosting $(\mathrm{n}=8)$ (Table 1). Rats were pair fed. Rat chow was rationed (chow was weighed to the nearest tenth of a gram) and increased over time to accommodate for growth. Effort was taken to ensure that food/caloric consumption was equal between the groups. If a rat did not consume all of its food, food intake was reduced the following day across groups. Rats not infused with Ang II (Groups 1 and 2) were implanted with osmotic minipumps containing vehicle solution $(0.01 \mathrm{~N}$ acetic acid

Table I The four experimental groups: dietary assignments for each of the four groups: over 4 weeks, rats were assigned to one of four regiments: I) control, 2) resveratrol supplemented (146 mg/d), 3) Ang Il-infused (80 $\mu \mathrm{g} / \mathrm{d})$, and 4) Ang II-infused plus resveratrol supplemented

\begin{tabular}{lll}
\hline Group & Minipump & Diet + supplement \\
\hline I. Control & Vehicle-I & Rat chow + vehicle-2 \\
2. Resveratrol & Vehicle-I & Rat chow + resveratrol \\
3. Ang II-treated & Ang II & Rat chow + vehicle-2 \\
4. Ang II plus resveratrol & Ang II & Rat chow + resveratrol \\
\hline
\end{tabular}

Notes: Vehicle-I for Ang II in minipumps is $0.9 \% \mathrm{NaCl}$ plus $0.01 \mathrm{~N}$ acetic acid. Vehicle-2 for dietary resveratrol supplement is dark frosting, $3 \mathrm{~g} / \mathrm{d}$.

Abbreviation: Ang II, angiotensin II. 
in sterile $0.9 \% \mathrm{NaCl}$; Table 1 ). In addition to the daily rat chow allotment, dark frosting was used as a vehicle for the resveratrol because the rats consumed it all voraciously; otherwise, the resveratrol has a bitter taste that rats do not like. Also, the dark opaque color prevented photodegradation of the resveratrol. Vehicle or resveratrol frosting was prepared daily by packing vehicle or resveratrol frosting into a $100 \mathrm{~mL}$ syringe and by weighing out $3 \mathrm{~g}$ on small 3 ' ceramic plates, which were placed on the floor of the caging. Resveratrol was thoroughly mixed into the frosting.

\section{Implantation of osmotic minipumps}

After 2 weeks of tail cuff training and at the beginning of dietary assignments, Model 2002 Alzet osmotic minipumps were primed overnight according to the manufacturer's instructions. Pumps were loaded with vehicle (Groups 1 and 2) or Ang II (Groups 3 and 4, $80 \mu \mathrm{g} / \mathrm{d}$ ) dissolved in sterile $0.9 \% \mathrm{NaCl}$ plus $0.01 \mathrm{~N}$ acetic acid. Rats were anesthetized with $50 \mathrm{mg} / \mathrm{kg}$ body weight nembutal (Ovation Pharmaceuticals, Deerfield, IL, USA) via intraperitoneal injection. The surgical procedure was performed using aseptic techniques on a heating pad to maintain constant body temperature. The incision site was shaved and cleaned with 70\% isopropyl alcohol, and a topical antiseptic bactericide, Betadine, was applied (Purdue Products, Stamford, CT, USA). An incision was made between the scapulae, and the minipumps were implanted subcutaneously. The incision site was closed with surgical staples. Buprenex (2.5 mg/kg) was administered to reduce postoperative pain (Reckitt Benckiser, Parsippany, NJ, USA). Rats were allowed to regain consciousness and recover on the hot pad before being returned to their cages.

\section{Short-term sodium balance studies}

Daily consumption of rat chow and frosting was monitored to measure sodium intake. After 3 weeks on the diets/treatments, rats were moved from regular caging to metabolic caging for the final 7 days and continued on their previously assigned diets. Rats were allowed to acclimate to the new environment for 1 day prior to the collection of urine. Urine from each cage was drained into clean $50 \mathrm{~mL}$ conical centrifuge tubes and was collected every 24 hours over 7 days. Urine volumes were recorded daily. Samples were transferred to Eppendorf tubes, spun at $10 \mathrm{~K} \mathrm{rpm}$ for 5 minutes to remove sediment, and placed in a $-80^{\circ} \mathrm{C}$ freezer. Daily sodium excretion values were calculated from sodium concentrations using a Nova Biomedical $\mathrm{pHOX}$ ultra (Waltham, MA, USA). Urine sodium concentrations were multiplied by the 24-hour volume to achieve the 24-hour sodium excretion. Total cumulative sodium balance was calculated by summing the sequential daily differences between intake and total sodium excretion and expressed in $\mu \mathrm{Eq} \pm$ standard error of the mean over a period of 7 days. ${ }^{22}$

\section{Creatinine clearance}

Creatinine was measured in the 24-hour urine collections and in the plasma during terminal sampling of trunk blood. Rats were euthanized (after 4 weeks) via decapitation using a rat guillotine (Harvard Bioscience, Cambridge, MA, USA) to accommodate the large volume of blood needed without the confounding influence of anesthesia. Blood samples were taken using either $200 \mu \mathrm{L}$ of $6 \%$ ethylenediaminetetraacetic acid in $0.9 \% \mathrm{NaCl}$ (Sigma-Aldrich Co.) or $100 \mu \mathrm{L}$ of sodium heparin (Sagent Pharmaceuticals, Schaumberg, IL, USA) as anticoagulants. Blood samples were spun at 3,000 rpm at $4{ }^{\circ} \mathrm{C}$ for 10 minutes, and the plasma was separated and stored at $-80{ }^{\circ} \mathrm{C}$ until creatinine analysis. Creatinine clearance was calculated by multiplying the concentration of urinary creatinine by the 24-hour urine volume, dividing by the plasma creatinine concentration, and then correcting to units of $\mathrm{mL} /$ min and kidney weight $(\mathrm{kw})$. Creatinine clearance was calculated from the urine samples collected during the last 2 days, while the rats were in a metabolic caging. Clearance values were expressed as $\mathrm{mL} / \mathrm{min} / \mathrm{gkw}$. Following blood collection, the gross physical appearance of the kidneys was assessed. Renal hydronephrosis was an exclusion criterion. Kidneys were excised and capsules removed, blotted, and weighed (Groups 2 and 4, n=8; Groups 1 and 3, n=7).

\section{Urinary nitric oxide assessment}

At day 27, a 24-hour urinary excretion of NO metabolites $\left(\mathrm{NO}_{2} / \mathrm{NO}_{3}\right)$ was measured across groups, while rats were housed in a metabolic caging. A total of $200 \mu \mathrm{L}$ of AntiAnti, an antibiotic and antimycotic, was placed in the urine collection tubes prior to urine collection to prevent degradation of the samples. NO concentration was measured using a $\mathrm{NO}_{2} / \mathrm{NO}_{3}$ Colorimetric Assay Kit (Cayman Chemical) via the Griess Reaction. NO excretion was calculated by multiplying the concentration by 24-hour urine volume. Units are expressed as $\mu \mathrm{mol} / 24 \mathrm{~h}$ (Groups 2 and 4, n=8; Groups 1 and $3, \mathrm{n}=7$ ).

\section{Urinary 8-isoprostane assessment}

At Day 26, urinary excretion of 8-isoprostane, a marker of oxidative stress, was measured across the groups. A total of $100 \mu \mathrm{L}$ of $0.005 \%$ 3,5-di-tert-4-butylhydroxytoluene was added to the urine collection tubes to prevent degradation 
of the samples. An 8-Isoprostane EIA kit was used to measure urinary concentrations (Cayman Chemical). Urinary concentrations were multiplied by urine volumes to reach isoprostane excretion values, expressed as nmol/24 h (Groups 2 and 4, n=8; Group 3, n=7; Group 1, n=6).

\section{Statistics}

When multiple comparisons between groups with one differing factor were performed, one-way analysis of variance with a Student-Newman-Keuls post hoc test was performed. When comparing two groups, an unpaired Student's $t$-test was performed. When comparing changes within a group, a paired Student's $t$-test was used. Our n-values were chosen to provide sufficient power (0.8) for our analyses. All data are presented as mean \pm standard error. In all cases, $P<0.05$ was considered statistically significant.

\section{Results}

\section{Blood pressure}

Blood pressure in Group 1, the control group, was unchanged from $121 \pm 2$ to $123 \pm 1 \mathrm{mmHg}$ over the course of 4 weeks (Figure 1). In Group 2, normal chow plus resveratrol, blood pressure also remained unchanged; $122 \pm 2$ to $126 \pm 5 \mathrm{mmHg}$ over 4 weeks. In Groups 3 and 4, blood pressure significantly and similarly increased in the 1 st week following the implantation of Ang II osmotic minipumps. In Group 3 (Ang II), blood pressure increased from $118 \pm 3$ to $132 \pm 4 \mathrm{mmHg}$, $P<0.04$, whereas in Group 4 (Ang II plus resveratrol), blood pressure increased from $122 \pm 1$ to $132 \pm 3 \mathrm{mmHg}, P<0.01$. However, by the end of 4 weeks, blood pressure in Group

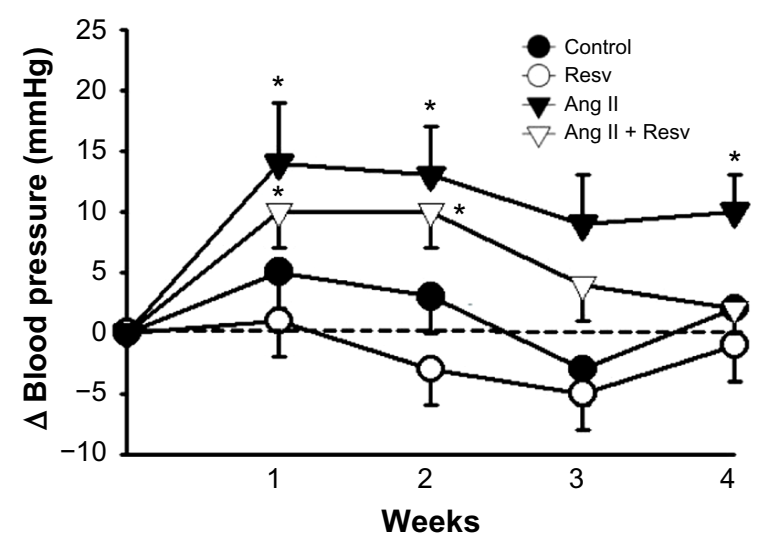

Figure I The change in systolic blood pressure over 4 weeks.

Notes: Systolic blood pressure remained unchanged in the control and resveratroltreated groups (Groups I and 2). Blood pressure initially increased with Ang II infusion (Groups 3 and 4), but between weeks 3 and 4, the increase in systolic blood pressure was reversed in the Ang II plus resveratrol group (Group 4). $* P<0.05$ versus week 0 control.

Abbreviations: Ang II, angiotensin II; Resv, resveratrol.
3 remained significantly elevated at $128 \pm 2 \mathrm{mmHg}$, while in Group 4 (Ang II plus resveratrol), the increase in blood pressure was reversed between weeks 3 and 4 . After 4 weeks, Group 3 (Ang II) was the only one in which blood pressure remained elevated.

\section{Body weight}

Figure 2 shows the changes in body weights over 4 weeks. Effort was made to ensure that the four groups of rats had similar caloric intake. There were no significant differences in body weight between the four groups at the beginning of the experiment: Groups 1) 243 $\pm 5,2) 248 \pm 8$, 3) $243 \pm 7$, and 4) $253 \pm 8 \mathrm{~g}$. Similarly, there were no differences in body weight after 4 weeks between the four

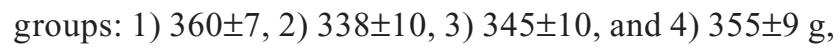
so that growth rate was similar in all the four groups.

\section{Sodium excretion and cumulative sodium balance}

To examine whether resveratrol consumption can increase sodium excretion and reduce positive cumulative sodium balance, we measured daily sodium intake, excretion, and cumulative sodium balance during the final week. Figure 3 displays daily sodium excretion between day 20 and day 27 . There were no differences between daily sodium excretion between the groups: 1) $1.17 \pm 0.17 \mu \mathrm{mol} \mathrm{Na} / 24 \mathrm{~h}$, 2) $1.23 \pm 0.09 \mu \mathrm{mol} \mathrm{Na} / 24 \mathrm{~h}, 3$ ) $1.12 \pm 0.14 \mu \mathrm{mol} \mathrm{Na} / 24 \mathrm{~h}$, and 4) $1.15 \pm 0.10 \mu \mathrm{mol} \mathrm{Na} / 24 \mathrm{~h}$ (Figure 3 ).

Between day 20 and day 27, there were no differences in cumulative sodium balance among all four groups: 1) $18.49 \pm 0.12 \mu \mathrm{Eq} \mathrm{NaCl}, 2) 17.75 \pm 0.16 \mu \mathrm{Eq} \mathrm{NaCl}$, 3) $17.91 \pm 0.17 \mu \mathrm{Eq} \mathrm{NaCl}$, and 4) $18.46 \pm 0.18 \mu \mathrm{Eq} \mathrm{NaCl}$

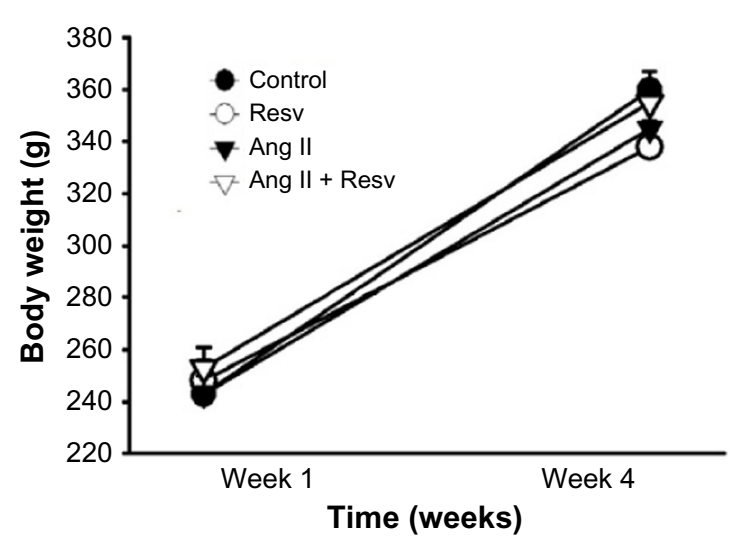

Figure 2 The change in body weight measured over 4 weeks. Notes: Body weight in all four groups significantly increased over 4 weeks $(P<0.05)$, but no differences in growth were seen between the four groups. Abbreviations: Ang II, angiotensin II; Resv, resveratrol. 


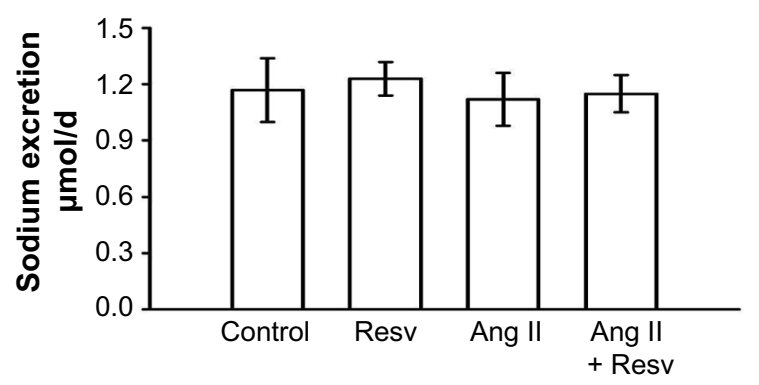

Figure 3 Mean 24-hour urinary sodium excretion measured over the final 7 days of the protocol.

Notes: There were no differences in sodium excretion between the four groups. Abbreviations: Ang II, angiotensin II; Resv, resveratrol.

(Figure 4). Overall, there were no differences in sodium excretion or cumulative sodium balance in the control or Ang II groups with or without resveratrol supplementation over the final 7 days when the Ang II-induced pressor response was reversed.

\section{Clearance of creatinine, urinary excretion of $\mathrm{NO}$ metabolites $\left(\mathrm{NO}_{2} / \mathrm{NO}_{3}\right)$ and 8-isoprostane}

We measured the clearance of creatinine, urinary excretion of $\mathrm{NO}$ metabolites $\left(\mathrm{NO}_{2} / \mathrm{NO}_{3}\right)$, and urinary excretion of 8 -isoprostane at the conclusion of the study. There were no differences in the clearance of creatinine between the four groups: 1) $0.40 \pm 0.06 \mathrm{~mL} / \mathrm{min} / \mathrm{gkw}, 2) 0.38 \pm 0.04 \mathrm{~mL} / \mathrm{min} /$ gkw, 3) $0.29 \pm 0.06 \mathrm{~mL} / \mathrm{min} / \mathrm{gkw}$, and 4) $0.32 \pm 0.05 \mathrm{~mL} / \mathrm{min} /$ gkw (Figure 5).

To test if sodium excretion was influenced by increased NO production, we sampled urinary excretion of $\mathrm{NO}_{2} / \mathrm{NO}_{3}$ in the four groups and obtained values of 1) $1271 \pm 197 \mu \mathrm{mol} / 24 \mathrm{~h}$, 2) $581 \pm 158 \mu \mathrm{mol} / 24 \mathrm{~h}, 3) 675 \pm 248 \mu \mathrm{mol} / 24 \mathrm{~h}$, and 4$)$ $383 \pm 70 \mu \mathrm{mol} / 24 \mathrm{~h}$ (Figure 6). Total $\mathrm{NO}_{2} / \mathrm{NO}_{3}$ excretion was decreased in the resveratrol-treated group, Group 2,

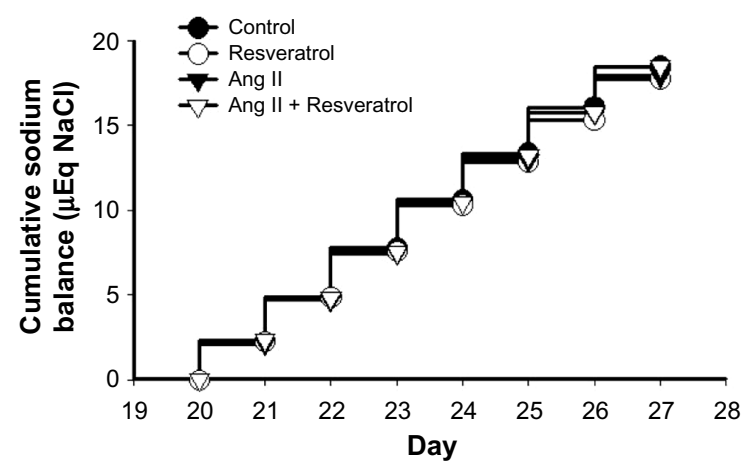

Figure 4 Cumulative sodium balance measured over the final 7 days of the protocol. Notes: There were no differences in cumulative sodium balance between the four groups.

Abbreviation: Ang II, angiotensin II.

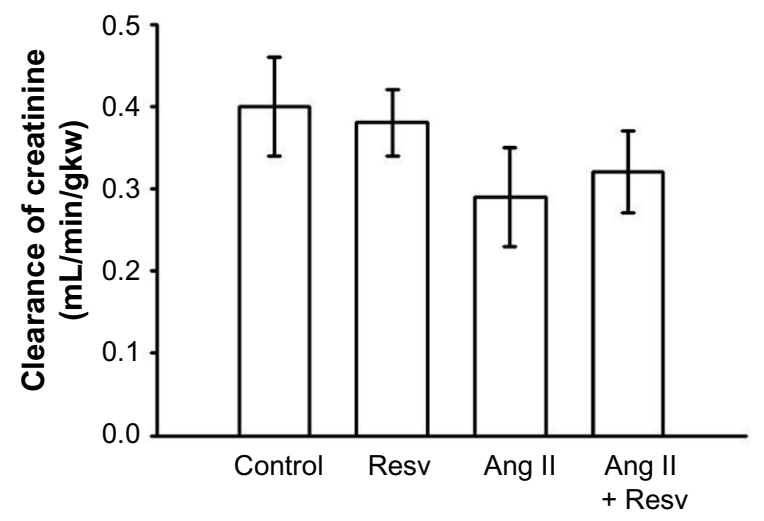

Figure 5 Clearance of creatinine: there were no differences in clearance of creatinine between the four groups.

Abbreviations: Ang II, angiotensin II; Resv, resveratrol.

compared to Group $1(P<0.05)$. Collectively, $\mathrm{NO}_{2} / \mathrm{NO}_{3}$ excretion was also decreased in the Ang II-treated groups compared to control $(P<0.05$, analysis of variance adjusted for multiple comparisons).

Urinary excretion of 8 -isoprostane excretion was 1) $63.85 \pm 19.39 \mathrm{nmol} / 24 \mathrm{~h}, 2) 73.57 \pm 22.02 \mathrm{nmol} / 24 \mathrm{~h}$, 3) $100.69 \pm 37.62 \mathrm{nmol} / 24 \mathrm{~h}$, and 4) $103.00 \pm 38.88 \mathrm{nmol} / 24 \mathrm{~h}$ (Figure 7). In Ang II-treated groups, the 8-isoprostane excretion had higher mean values, but this did not achieve statistical significance. Overall, there were no significant differences between the four groups.

\section{Discussion}

We hypothesized that chronic ingestion of resveratrol (146 mg/d) over 4 weeks would reverse Ang II-induced increases in blood pressure by decreasing oxidative stress and sodium reabsorption (and thus cumulative sodium balance) through a NO-dependent mechanism. To test our hypothesis, we selected a low dose of Ang II infusion $(80 \mu \mathrm{g} / \mathrm{d})^{23}$ that would only induce a mild pressor effect, as we were uncertain

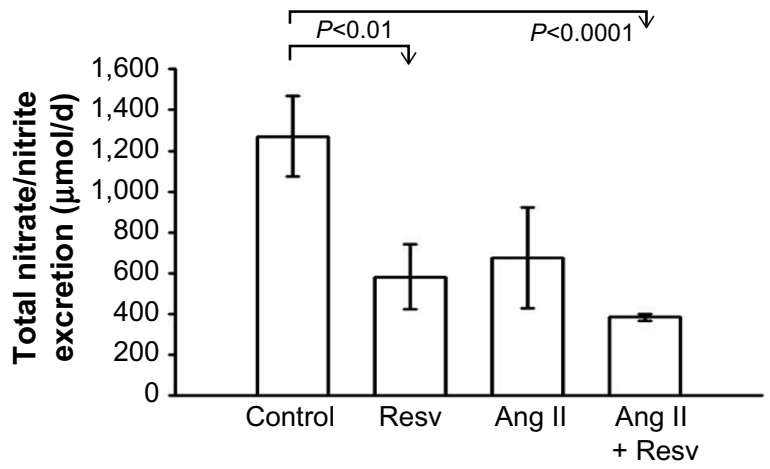

Figure 6 Urinary excretion of $\mathrm{NO}_{2} / \mathrm{NO}_{3}$. Notes: Resveratrol did not increase excretion of nitric oxide metabolites. $\mathrm{NO}_{2}$ I $\mathrm{NO}_{3}$ excretion was decreased in Ang II plus resveratrol group.

Abbreviations: Ang II, angiotensin II; Resv, resveratrol. 


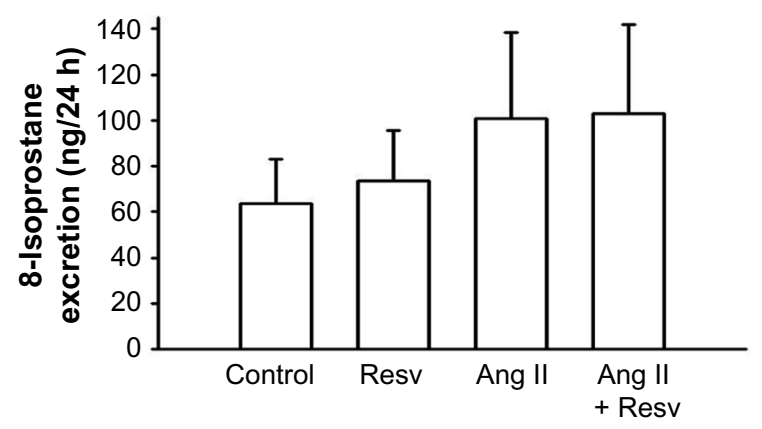

Figure 7 Urinary excretion of 8-isoprostane.

Notes: Resveratrol did not decrease renal oxidative stress, as no differences were observed between groups in urinary excretion of 8-isoprostane.

Abbreviations: Ang II, angiotensin II; Resv, resveratrol.

if our limited dietary resveratrol supplementation would be sufficient to reverse the rigorous pressor effect induced by a high dose of Ang II. We found that resveratrol treatment was unable to prevent Ang II-induced increases in blood pressure. However, with extended resveratrol consumption, the Ang II-induced increases in blood pressure were reversed.

Resveratrol has been reported to lower blood pressure. ${ }^{3,24}$ Bhatt et $\mathrm{al}^{25}$ used resveratrol dissolved in drinking water $(50 \mathrm{mg} / \mathrm{L})$ in SHR and reported that SHR given resveratrol had lower systolic blood pressure than nontreated SHR (221 \pm 2 vs $196 \pm 3 \mathrm{mmHg}$ ). Overall, the existing literature referencing resveratrol and Ang II in whole animal studies is surprisingly sparse. Polydatin, a resveratrol glucoside, was delivered in an Ang II-induced model of hypertension by Zhang et al, ${ }^{26}$ who found that the chronic infusion of Ang II significantly increased systolic blood pressure from $120 \pm 3$ to $162 \pm 7 \mathrm{mmHg}$ with Ang II, and oral administration of polydatin for 5 weeks did not decrease the pressor effect of Ang II. Dolinsky et $\mathrm{al}^{3}$ implanted mice with osmotic minipumps to deliver Ang II $(1.4 \mathrm{mg} / \mathrm{kg} / \mathrm{d})$ and placed mice on a diet containing resveratrol (using $\sim 320 \mathrm{mg} / \mathrm{kg} / \mathrm{d}$ resveratrol). Following 2 weeks of resveratrol treatment, the Ang II plus resveratrol group had lower blood pressure when compared to the Ang II-infused alone. They also showed that resveratroltreated SHR maintained lower systolic blood pressures than control SHR. However, even with resveratrol treatment, the SHR still had systolic blood pressures $>160 \mathrm{mmHg}^{3}$ Inanaga et al, ${ }^{27}$ using C57/B6 mice, showed that resveratrol treatment blunted Ang II-induced increases in systolic blood pressure. However, their reported systolic blood pressure values using tail cuff measurements in mice were unusually and uncharacteristically low.

During the course of our 4-week study, the control and normal chow plus resveratrol groups (Groups 1 and 2) showed no increase in blood pressure. However, both Ang II-infused groups (Groups 3 and 4) saw similar, significant increases in systolic blood pressure in the 1st week. Resveratrol treatment was unable to prevent the initial pressor effects of mild Ang II infusion. Blood pressure remained elevated in our Ang II group, but blood pressure in the Ang II plus resveratrol group returned to control levels between weeks 3 and 4. Javkhedkar et al ${ }^{28}$ used 3- to 4-week-old SHR and normotensive controls treated for 9 weeks with resveratrol $(50 \mathrm{mg} / \mathrm{L})$ or vehicle in their drinking water. They reported that SHR with resveratrol treatment had lower mean arterial pressure during weeks 7-12, though blood pressure was not returned to normotensive levels. These data corroborate our findings that resveratrol treatment is unable to prevent the onset of hypertension, but there may be a long-term, temporal effect of resveratrol reversing increased blood pressure after a few weeks of treatment.

In our previous studies, ${ }^{29}$ we showed that resveratrol acted as an acute renal vasodilator working through increasing $\mathrm{NO}$ and decreasing reactive oxygen species. We also found ${ }^{8}$ that subvasodilatory doses of sustained resveratrol administration could induce natriuresis without affecting glomerular filtration rate. This suggested a direct tubular action of resveratrol. ${ }^{8}$ We wanted to test whether a dietary resveratrol supplement would increase sodium excretion through an NO-dependent mechanism, ultimately leading to a decreased positive sodium balance. Our approach of metabolic studies to measure sodium intake, sodium excretion, and sodium balance in resveratrol-treated rats represented a novel approach to determine possible tubular sodium effects of resveratrol.

We found that resveratrol consumed in the diet did not increase sodium excretion in Group 2 (normal rat chow plus resveratrol) nor did it increase sodium excretion in Group 4. No differences in urinary sodium excretion or cumulative sodium balance existed between any of the groups. Contrary to our hypothesis, we conclude that resveratrol had no effect in increasing sodium excretion or diminishing positive sodium balance. Further, our dose of Ang II produced a pressor effect and increased blood pressure during the initial weeks, but Ang II treatment at this dose did not significantly increase measurable sodium retention in our model. Thus, the mechanism by which resveratrol lowers blood pressure does not appear to be linked to sodium handling within the nephron or by reducing overall sodium retention.

Bertelli et $\mathrm{al}^{30}$ in a model of acute kidney failure induced by ischemia showed that rats pretreated with resveratrol raised urinary excretion of cGMP, a marker for NO synthase activity. We did not find that resveratrol stimulated an increase in the 
urinary excretion of NO metabolites. Contrary to our expectations, resveratrol treatment significantly decreased excretion of NO metabolites. This finding is clearly contrary to our hypothesis, and an obvious explanation is lacking. Our study suggests that chronic dietary consumption of resveratrol has no effect on sodium excretion. The in vivo biological effects of resveratrol may be severely limited by low bioavailability. Although resveratrol is well absorbed and can readily enter the cell by diffusion, resveratrol is not maintained in high levels within the blood stream. ${ }^{31}$ This may explain differences in our acute and chronic studies.

Oxidative stress is determined by the balance between the generation of reactive oxygen species and opposing antioxidant systems. ${ }^{32}$ The renal medulla is the primary site of superoxide in the kidney and also the location of thick ascending limbs of juxtamedullary nephrons. In our previous work, ${ }^{29}$ we showed that resveratrol-induced renal vasodilation was in part due to a reduction in reactive oxygen species and/or increase in NO bioavailability. Resveratrol treatment has been shown to lower 8-isoprostane levels in diabetic rats. ${ }^{20}$ We measured urinary excretion of 8-isoprostane, a reliable index of renal oxidative stress, to test if resveratrol would potentially lower oxidative stress. Ang II-infused groups, 8-isoprostane excretion, had higher mean values but not enough to achieve statistical significance. We saw no decrease in 8-isoprostane excretion with resveratrol treatment. Thus, we conclude that resveratrol supplementation had no effect on oxidative stress within our model.

Overall, the reductions in blood pressure in this study do not seem to be linked to changes in NO or reducing oxidative stress in our model. An unknown mechanism we did not account for may explain why resveratrol reduced blood pressure in the final week of our study, such as vascular relaxation, ${ }^{33}$ a central effect, or some other parameter as reviewed by Zorodky et al. ${ }^{34}$

To evaluate the effect of Ang II and resveratrol on renal function, we measured the clearance of creatinine at the conclusion of the protocol. Ang II-induced hypertension is associated with decreased glomerular filtration rate. ${ }^{38}$ In our study, the clearance of creatinine in the Ang II group (Group 3) was not significantly lower when compared to the non-Ang II-treated groups. There were no differences in the clearance of creatinine between the four groups after 4 weeks. This may reflect our model of low-dose Ang II.

\section{Conclusion}

In summary, our findings suggest that resveratrol is unable to prevent increases in blood pressure due to Ang II. Rigorous metabolic studies show that resveratrol supplementation does not increase urinary sodium excretion, decrease cumulative sodium balance, or decrease blood pressure through a sodiumdependent mechanism. However, we did observe a reversal of the Ang II increase in blood pressure with chronic dietary resveratrol treatment following 3-4 weeks of treatment. In view of our data, chronic supplementation with resveratrol may have mild depressor effects, but these do not seem to be due to natriuresis or chronically enhanced NO synthesis.

\section{Perspectives}

Resveratrol research and positive outcomes are debatable, perhaps due to the numerous disparate findings. In the early 1990s, Renaud and de Lorgeril proposed that wine consumption might possess beneficial effects. The "resveratrol paradox" (a coined term designed to elicit intrigue) describes an observation within French society in which there are improved cardiovascular outcomes related to their wine intake, despite the French consumption of a high-fat diet. In a review by Zorodky et al, ${ }^{34}$ they highlight a variety of mechanisms by which resveratrol reduces blood pressure in animal models of hypertension. Liu et al, ${ }^{35}$ in a meta-analysis of humans treated with resveratrol dietary supplementation, found that resveratrol had no effect on blood pressure, and only a high dose of resveratrol consumption $(>150 \mathrm{mg} / \mathrm{d})$ was associated with lowering systolic blood pressure. However, a criticism of the meta-analysis by Liu et $\mathrm{al}^{35}$ is that the $n$-value in the resveratrol hypotensive subgroup was extremely low $(<100)$.

Despite the increase in the total wine consumption on a per capita basis within the USA during the past 2 decades (US Wine Institute), heart disease remains a leading cause of death for men and women within the USA. ${ }^{36,37}$ Correlative studies do not seem to support resveratrol to reduce the risk cardiovascular disease. The results of the Invecchiare in Chianti (InCHIANTI), ${ }^{38}$ a longitudinal study of elderly individuals living in two Italian towns, followed over a longterm basis from 1998 to 2009 with follow-up evaluations every 3 years, found no correlation between total urinary resveratrol metabolites and prevalence of cancer, cardiovascular disease, markers of inflammation, and cause of mortality. A recent editorial in Pharmacological Research by editorin-chief, Francesco Visioli, adeptly summarizes the failures of resveratrol research. ${ }^{39}$ Paraphrasing from "The resveratrol fiasco", resveratrol has shown no proven human activity. Use of nonphysiological concentrations and cell culture experiments does not yield translatable clinical outcomes. ${ }^{39}$ Further, perhaps in a definitive review of past resveratrol clinical trials, 
Tang et $\mathrm{al}^{40}$ reported no resounding evidence that resveratrol lowers blood pressure in humans.

We are cognizant that resveratrol treatment was not efficacious in preventing increased blood pressure with low-dose Ang II. To that end, resveratrol supplementation may not act as an effective antihypertensive, especially with a high dose of Ang II. Our sodium measurements were obtained during the final week and not during the introduction of Ang II. In light of our data, the resveratrol paradox frequently mentioned in the literature may not be a paradox. Exogenous antioxidant supplements have not been proven to lower blood pressure in humans. The recent availability of resveratrol as dietary supplements at levels that are orders of magnitude higher than what wine, fruits, or nuts may contain could help end the resveratrol debate with further study. Overall, the current literature suggests that resveratrol may exert distinct physiological effects in controlled animal models, but the current data do not suggest efficacy in prevention or diminishment of hypertension in humans.

\section{Acknowledgment}

This research was supported by funding from the National Institutes of Health Grant 5P01HL090550-05.

\section{Disclosure}

The authors report no conflicts of interest in this work.

\section{References}

1. Baur JA and Sinclair DA. Therapeutic potential of resveratrol: the in vivo evidence. Nat. Rev. Drug Discov. 2006;6:493-506.

2. Bhatt JK, Thomas S, Nanjan MJ. Resveratrol supplementation improves glycemic control in type 2 diabetes mellitus. Nutr Res. 2012;32(7):537-541.

3. Dolinsky VW, Chakrabarti S, Pereira TJ, et al. Resveratrol prevents hypertension and cardiac hypertrophy in hypertensive rats and mice. Biochim Biophys Acta. 2013;1832(10):1723-1733.

4. Hall JE. Control of sodium excretion by angiotensin II: intrarenal mechanisms and blood pressure regulation. Am J Physiol. 1986; 250(6 Pt 2):R960-R972.

5. Majid DS, Williams A, Kadowitz PJ, Navar LG. Renal responses to intra-arterial administration of nitric oxide donor in dogs. Hypertension. 1993;22(4):535-541.

6. Ortiz PA and Garvin JL. Role of Nitric oxide in the regulation of nephron transport. Am J Renal Physiol. 2002;282(5):F777-F784.

7. Mattson DL, Roman RJ, Cowley AW Jr. Role of nitric oxide in renal papillary blood flow and sodium excretion. Hypertension. 1992; 19(6 Pt 2):766-769.

8. Gordish KL and Beierwaltes WH. Sustained resveratrol infusion increases natriuresis independent of renal vasodilation. Physiol Rep. 2014;2(9):e12144

9. Gonzalez-Vicente A, Cabral PD, Garvin JL. Resveratrol increases nitric oxide production in the rat thick ascending limb via $\mathrm{Ca} 2+/$ calmodulin. PLoS One. 2014;14;9(10):e110487.

10. Wallerath T, Deckert G, Ternes T, et al. Resveratrol, a polyphenolic phytoalexin present in red wine, enhances expression and activity of endothelial nitric oxide synthase. Circulation. 2002;10613: 1652-1658.
11. Wallerath T, Poleo D, Li H, Förstermann U. Red wine increases the expression of human endothelial nitric oxide synthase: a mechanism that may contribute to its beneficial cardiovascular effects. $J$ Am Coll Cardiol. 2003;41(3):471-478.

12. Mattson DL, Lu S, Nakanishi K, Papanek PE, Cowley AW Jr. Effect of chronic renal medullary nitric oxide inhibition on blood pressure. Am J Physiol. 1994;266(5 Pt 2):H1918-H1926.

13. Ortiz PA, Hong NJ, Wang D, Garvin JL. Gene transfer of eNOS to the thick ascending limb of eNOS-KO mice restores the effects of L-arginine on $\mathrm{NaCl}$ absorption. Hypertension. 2003;42(4):674-679.

14. Ortiz PA and Garvin JL. NO Inhibits $\mathrm{NaCl}$ absorption by rat thick ascending limb through activation of cGMP-stimulated phosphodiesterase. Hypertension. 2001;37(2 Pt 2):467-471.

15. Wang CT, Zou LX, Navar LG. Renal responses to AT1 blockade in angiotensin II-induced hypertensive rats. J Am Soc Nephrol. 1997;8(4):535-542.

16. Garvin JL. Angiotensin stimulates glucose and fluid absorption by rat proximal straight tubules. J Am Soc Nephrol. 1990;1(3):272-277.

17. Haas JA, Krier JD, Bolterman RJ, Juncos LA, Romero JC. Low-dose angiotensin II increases free isoprostane levels in plasma. Hypertension. 1999;34(4 Pt 2):983-986.

18. Ortiz MC, Sanabria E, Manriquez MC, Romero JC, Juncos LA. Role of endothelin and isoprostanes in slow pressor responses to angiotensin II. Hypertension. 2001;37(2 Pt 2):505-510.

19. Chiavaroli A, Brunetti L, Orlando G, et al. Resveratrol inhibits isoprostane production in young and aged rat brain. J Biol Regul Homeost Agents. 2010;24(4):441-446.

20. Mohammadshahi M, Haidari F, Soufi FG. Chronic resveratrol administration improves diabetic cardiomyopathy in part by reducing oxidative stress. Cardiol J. 2014;21(1):39-46.

21. Kim MY, Lim JH, Youn HH, et al. Resveratrol prevents renal lipotoxicity and inhibits mesangial cell glucotoxicity in a manner dependent on the AMPK-SIRT1-PGC1 $\alpha$ axis in $\mathrm{db} / \mathrm{db}$ mice. Diabetologia. 2013;56(1):204-217.

22. Beierwaltes WH, Arendshorst WJ, Klemmer PJ. Electrolyte and water balance in young spontaneously hypertensive rats. Hypertension. 1982;4(6):908-915.

23. Rhaleb NE, Yang XP, Nanba M, Shesely EG, Carretero OA. Effect of Chronic Blockade of the Kallikrein-Kinin System on the Development of Hypertension in Rats. Hypertension. 2001;37(1):121-128.

24. Thandapilly SJ, LeMaistre JL, Louis XL, Anderson CM, Netticadan T, Anderson HD. Vascular and cardiac effects of grape powder in the spontaneously hypertensive rat. Am J Hypertens. 2012;25(10):1070-1076.

25. Bhatt SR, Lokhandwala MF, Banday AA. Resveratrol prevents endothelial nitric oxide synthase uncoupling and attenuates development of hypertension in spontaneously hypertensive rats. Eur J Pharmacol. 2011;667(1-3): 258-64.

26. Zhang Q, Tan Y, Zhang N, Yao F. Polydatin prevents angiotensin IIinduced cardiac hypertrophy and myocardial superoxide generation. Exp Biol Med. 2014;0:1-10.

27. Inanaga $\mathrm{K}$, Ichiki $\mathrm{T}$, Matsuura $\mathrm{H}$, et al. Resveratrol attenuates angiotensin II-induced interleukin- 6 expression and perivascular fibrosis. Hypertens Res. 2009;32(6):466-471.

28. Javkhedkar AA, Quiroz Y, Rodriguez-Iturbe B, Vaziri ND, Lokhandwala MF, Banday AA. Resveratrol restored Nrf2 function, reduced renal inflammation, and mitigated hypertension in spontaneously hypertensive rats. Am J Physiol Regul Integr Comp Physiol. 2015;308(10):R840-R846.

29. Gordish KL and Beierwaltes WH. Resveratrol induces acute endothelium renal vasodilation mediated through nitric oxide and reactive oxygen species scavenging. Am J Renal Physiol - Renal Physiol. 2014;306(5):F542-F550.

30. Bertelli AA, Migliori M, Panichi V, et al. Resveratrol, a component of wine and grapes, in the prevention of kidney disease. Ann N Y Acad Sci. 2002;957:230-238.

31. Amri A, Chaumeil JC, Sfar S, Charrueau C. Administration of resveratrol: What formulation solutions to bioavailability limitations? J Control Release. 2012;158(2):182-193. 
32. Kitiyakara C, Chabrashvili T, Chen Y, et al. Salt intake, oxidative stress, and renal expression of NADPH oxidase and superoxide dismutase. J Am Soc Nephrol. 14(11):2775-2782, 2003.

33. Dalaklioglu S, Ozbey G. The potent relaxant effect of resveratrol in rat corpus cavernosum and its underlying mechanisms. Int J Impot Res. 2013;25(5):188-193.

34. Zorodky BN, Robertson IM, Dyck JR.Preclinical and clinical evidence for the role of resveratrol in the treatment of cardiovascular diseases. Biochim Biophys Acta. 2015;1852(6):1155-1177.

35. Liu Y, Ma W, Zhang P, He S, Huang D. Effect of resveratrol on blood pressure: a meta-analysis of randomized controlled trials. Clin Nutr. 2015;34(1):27-34.

36. Kochanek KD, Xu J, Murphy SL, et al. Deaths: Final Data for 2009. National vital statistics reports; National Center for Health Statistics. $2012 ; 60(3) ; 1-117$.
37. Roger VL, Go AS, Lloyd-Jones DM, et al. Heart disease and stroke statistics - 2012 update: a report from the American Heart Association. Circulation. 2012;125(1):e2-220.

38. Semba RD, Ferrucci L, Bartali B, et al. Resveratrol levels and all-cause mortality in older community-dwelling adults. JAMA Intern Med. 2014;174(7):1077-1084.

39. Visioli F. The resveratrol fiasco. Pharmacol Res. 2014;90:87.

40. Tang PC, Ng YF, Ho S, Gyda M, Chan SW. Resveratrol and cardiovascular health-promising therapeutic or hopeless illusion? Pharmacol Res. 2014;90:88-115.

Integrated Blood Pressure Control

\section{Publish your work in this journal}

Integrated Blood Pressure Control is an international, peer-reviewed open-access journal focusing on the integrated approach to managing hypertension and risk reduction. Treating the patient and comorbidities together with diet and lifestyle modification and optimizing healthcare resources through a multidisciplinary team approach constitute key features of the journal. This journal is indexed on American Chemical Society's Chemical Abstracts Service (CAS). The manuscript management system is completely online and includes a very quick and fair peerreview system, which is all easy to use. Visit http://www.dovepress.com/ testimonials.php to read real quotes from published authors.

Submit your manuscript here: http://www.dovepress.com/integrated-blood-pressure-control-journal 